\title{
REALISMO, VERSUS NEORROMANTICISMO PICTÓRICO: UN TEMA TAURINO RECURRENTE
}

\section{REALISME, VERSUS NEOROMANTICISM PINCTORIAL: A RECURRING THEME TAURINO}

\author{
Gerardo Pérez Calero \\ Universidad de Sevilla, España \\ gcalero@us.es
}

\begin{abstract}
Este trabajo pone de manifiesto cómo los grandes artistas tienen seguidores temáticos que realizan copias o versiones de cuadros afamados.

Palabras clave: Realismo y Neorromanticismo pictóricos del siglo XIX.
\end{abstract} paintings.

This work shows how the great artists have followers that back or thematic versions of famous

Key words: Pictorial realism and romanticism of the nineteenth century.

Sabido es que el Realismo irrumpe en la pintura española algo más tardíamente que lo hace en Francia en los comedios de la centuria decimonónica; esto es, con ocasión del destronamiento de Isabel II provocado por la revolución septembrina de 1868, si bien la convocatoria de las Exposiciones Nacional de Bellas Artes en 1856 y el consecuente triunfo de la pintura de historia habían supuesto un cambio temático que allanaron el camino al éxito de la nueva estética.

En este ambiente de innovaciones, hay artistas que habiendo conocido el Romanticismo en sus primeros años de formación, derivan después hacia el Realismo para tornar posteriormente hacia un Neorromanticismo de cuño fortuniano. También algunos de estos creadores renuevan la temática costumbrista de origen romántico actualizando aquellas representaciones lúdicas andaluzas como es el caso singular de las taurinas, que tanto gustaron a los pintores extranjeros sobre todo ingleses, como son Robert Kemm (1837-1895), John Haynes Williams (1836-1908) o Alexander Hohenloe Burr (1837-1899). 
El primer protagonista de este trabajo es el pintor sevillano José Jiménez Aranda (1837-1903), quien en su obra "Un lance en la plaza de toros", firmada en 1870, (Figura 1) hace gala de un realismo de acontecimiento social de impacto en la arena de la Real Maestranza de Sevilla. Cual reportero gráfico, oculta la víctima para evitar al espectador escena tan cruenta, como también hará veinte años después en su cuadro parisino titulado "Una desgracia".

El artista, que por entonces se hallaba en Madrid pero que no perdía el recuerdo de las apoteósicas tardes taurinas vividas en el coso hispalense, interpreta con estudiadas poses a cada uno de los espectadores de la corrida de toros situados en el palco y cuya mayoría se esfuerza por centrar la mirada a la izquierda en una supuesta cogida del picador, a juzgar por la galopada suelta del caballo que huye despavorido mientras a la derecha se ve tendido sobre el albero otro equino destripado. No pierde ocasión de interpretar a cada uno de los personajes individualmente: el caballero que ocupa el centro de la composición y se agarra al fuste de la columna mientras se apoya como puede; otro que permanece de pie y con bastón sostenido por dos sillas; el de más a la derecha que acerca a sus ojos unos pequeños prismáticos; o el caballero de más edad que prefiere permanecer al margen de lo que acontece en el ruedo. Se afanan en no perderse detalle, aunque para ello haya que subirse a una silla de enea o tirar alguna otra por la rapidez para incorporarse. Por su parte, todas las mujeres, menos una, ocultan su rostro para no ser partícipes del trágico suceso; una, volviendo su mirada hacia el interior del palco; otra, iniciando su salida a requerimiento de su marido. A destacar, la rica indumentaria de la dama situada en primer plano como una mancha de color de blancos y pálidos rosas con el amarillo del mantón y el toque rojo de la flor en el pelo.

Además, el autor documenta fielmente la escena taurina en un contexto propio del realismo pictórico. Para ello, por una parte interpreta acorde con la época la indumentaria de los personajes burgueses con chaquetas y tocados con sombreros hongos que aparecen en los palcos 1 y 2 frente al proletariado de los tendidos de sol interpretado en diluidas masas de color destacando las manchas de las sombrillas rojas y azules; por otra, plasma de manera precisa la arquitectura del coso en el estado en que se encontraba entonces desde 1760; esto es, aún abierta

${ }^{1}$ Óleo sobre tabla, 51 x $46 \mathrm{~cm}$. Firmado en el ángulo inferior izquierdo: J. Jiménez/Sevilla, 1870. Colección Carmen Thyssen-Bornemisza en préstamo gratuito al Museo Carmen Thyssen Málaga.

Sobre el pintor, véase nuestro libro: José Jiménez Aranda. Col. “Arte Hispalense”, no 29. Diputación de Sevilla, 1982. B. de Pantorba en su libro sobre el pintor (1972) dice que figuró en la Exposición nacional de Bellas Artes de 1871 donde fue premiado con medalla de tercera clase. Añade que fue reproducido en la revista de Barcelona "Lecturas" con un breve artículo titulado "Jiménez Aranda, el pintor que todo se lo debió a sí mismo". 
en el anillo de los palcos cuyo cerramiento terminaría el arquitecto Juan Talavera entre 1880 y el año siguiente.

Tras su estancia romana (1872-1875), en 1880 Jiménez Aranda firma en Sevilla una nueva versión con variantes y a mayor tamaño de aquel tema taurino pero ahora con claras referencias neorrománticas propias del casaconismo, que entonces practicaba con fruición ${ }^{2}$. (Figura 2)

Mantiene en líneas generales el acontecimiento taurino prescindiendo de la visión del caballo destripado tendido en el albero. El marco es el mismo, plasmando el estado arquitectónico de la Plaza, aunque reduciendo la fábrica de la catedral, ocultando gran parte de la iglesia del Sagrario de la propia seo, situando a la Giralda en el arco de la derecha, incluyendo una casa en el arco de la izquierda y modificando los palcos fronteros. Sin embargo, lo más importante es el carácter de obra goyesca y neorromántica que le confieren los personajes vestidos con casacas, medias blancas y tocados con tricornios o bicornios a excepción del caballero situado en el extremo izquierdo que se cubre con sombrero de copa, tal como figuraba en la versión anterior y signo inequívoco de que estamos en otro tiempo. Tales personajes, en esta segunda versión, manifiestan ahora ligeras variantes en sus inclinaciones y posturas, más evidente en la dama situada a la izquierda que vuelve la cabeza con decisión para evitar la visión del lance; la posición de la pierna del caballero situado en el centro subido a la silla, y objetos como el bastón que ahora se encuentra en el suelo.

La obra tuvo tal repercusión en el panorama artístico de la época, que fue objeto de atención en diversas revistas europeas ${ }^{3}$.

${ }^{2} \mathrm{O} / 1.168$ x141 cm. Colección particular de Madrid. En el bastidor del cuadro reza la inscripción: "José Jiménez Aranda Rue Nicolas Paris Un accident à la course de Taureaux".

Esta nueva versión aparece titulada en los medios como: "En la plaza de toros de Sevilla a principios de siglo: Emoción de una cogida." Tuvo como la primera gran éxito de crítica y figuró en el Salón de París de 1880, en la Exposición General de Bellas Artes de Barcelona de 1891 y en la Internacional de Chicago dos años después en donde fue premiada con medalla. Dice B. de Pantorba (1972) que en el catálogo de este certamen se indicaba su precio en 30.000 pesetas. Adquirido primeramente por el marchante francés M. Goupil, éste lo vendió al coleccionista Peña, de Buenos Aires, y a él se lo compró el también coleccionista argentino Galdaracena. En aquel entonces se hallaba en la colección bonaerense de Lloveras Páez. También figuró, en 1904 en la exposición de pintura española celebrada en la citada ciudad a iniciativa de José Artal. Lo reprodujo "La Ilustración Española y Americana" el 15 de agosto de 1880 con comentario de Manuel Bosch y también de Jacinto Octavio Picón.

La pieza se subastó en el Christies de Nueva York (subasta 8758, lote 117) y posteriormente en Ansorena de Madrid en enero de 2014 con un precio de salida de 60.000 euros.

${ }^{3}$ La Ilustración Española y Americana. Madrid, 15 de agosto de 1880. También se hizo eco de él una publicación alemana de la época. 
Las dos escenas taurinas anteriormente citadas, especialmente la segunda, llamarían la atención del madrileño Eugenio Lucas Villaamil (1858-1918), muy aficionado a semejante temática como seguidor artístico de su padre, el romántico casticista madrileño Eugenio Lucas Velázquez (Madrid, 1817-1870), y como él admirador de Goya, quien debió verla reproducida y comentada en la citada revista española ${ }^{4}$. De tal suerte, unos cinco años después de aquella última versión del pintor sevillano, hizo la suya propia en la línea de su habitual estilo neogo$\operatorname{yesco}^{5}$ (Figura 3). Para ello, y en un tono más desenfadado, nos muestra su admiración por el maestro aragonés, lo que supone la alteración iconográfica respecto, no solo a la primera versión de Jiménez Aranda, sino incluso de la segunda. En este sentido, en lugar de traducir la obra en clave neorromántica, como lo hizo en 1880 el pintor sevillano, la anticipa de manera anacrónica siguiendo los presupuestos casticistas goyescos; esto es, incorporando una maja bajo cada arco del palco, cambiando las indumentarias y los sombreros de tres picos por el de copa, prescindiendo de la visión del caballo corriendo despavorido por la arena, e incluyendo otras variantes como la ubicación del joven a la izquierda de la representación que se coloca más próximo al espectador e imposibilitado de ver la acción impetuosa que sucede en el ruedo.

Esta obra de 1885, como la pareja de temática semejante que también firma Eugenio Lucas este mismo año con los títulos de "Entrada a los toros, sol" y "Salida de los toros, lluvia" (col. Thyssen), están ya fuera de los gustos del público y de la crítica por los casacones, cuya producción estaba agotada hacía tiempo pero que pintores de éxito en el género como Jiménez Aranda llevaron a sus últimas consecuencias hasta incluso entrada la década siguiente, gracias a su talento para interpretar una temática que Mariano Fortuny había rescatado como propia del romanticismo isabelino y con precisión del casticismo goyesco.

Fecha de recepción: 11 de septiembre de 2014

Fecha de aceptación: 28 de noviembre de 2014

\footnotetext{
${ }^{4}$ Ibidem.

${ }^{5} \mathrm{O} / 1$. de 80,5 x 100. Firmado en el ángulo inferior derecho: E. Lucas. Fue subastada en "Alcalá Subastas" de Madrid los días 21 y 22 de mayo de 2014. Lote 234 A. Hoy se encuentra en el Museo Carmen Thyssen de Málaga.
} 


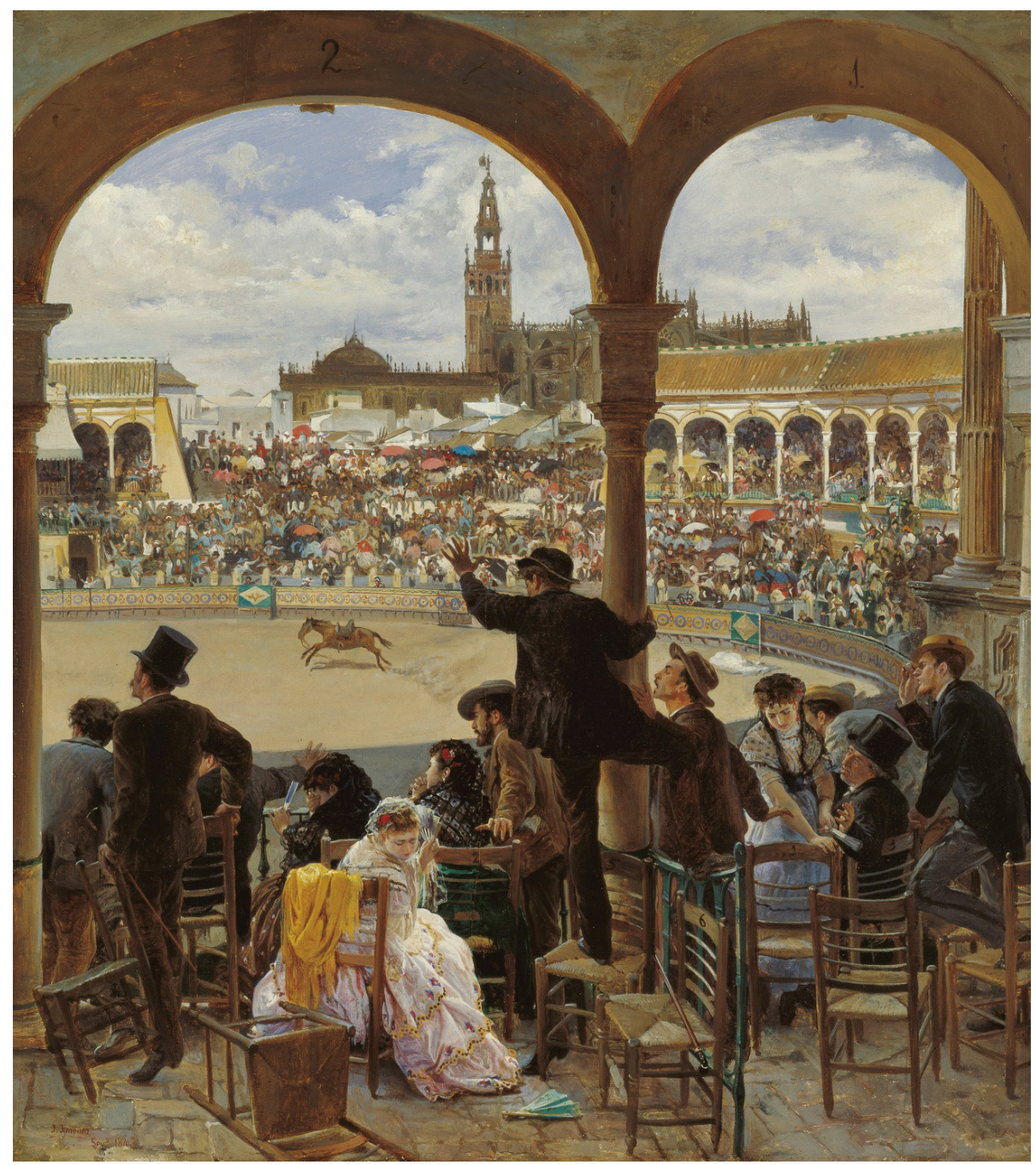

Figura 1. José Jiménez Aranda. "Un lance en la Plaza de Toros". O/t. 51 x $46 \mathrm{~cm}$. Sevilla, 1870. 


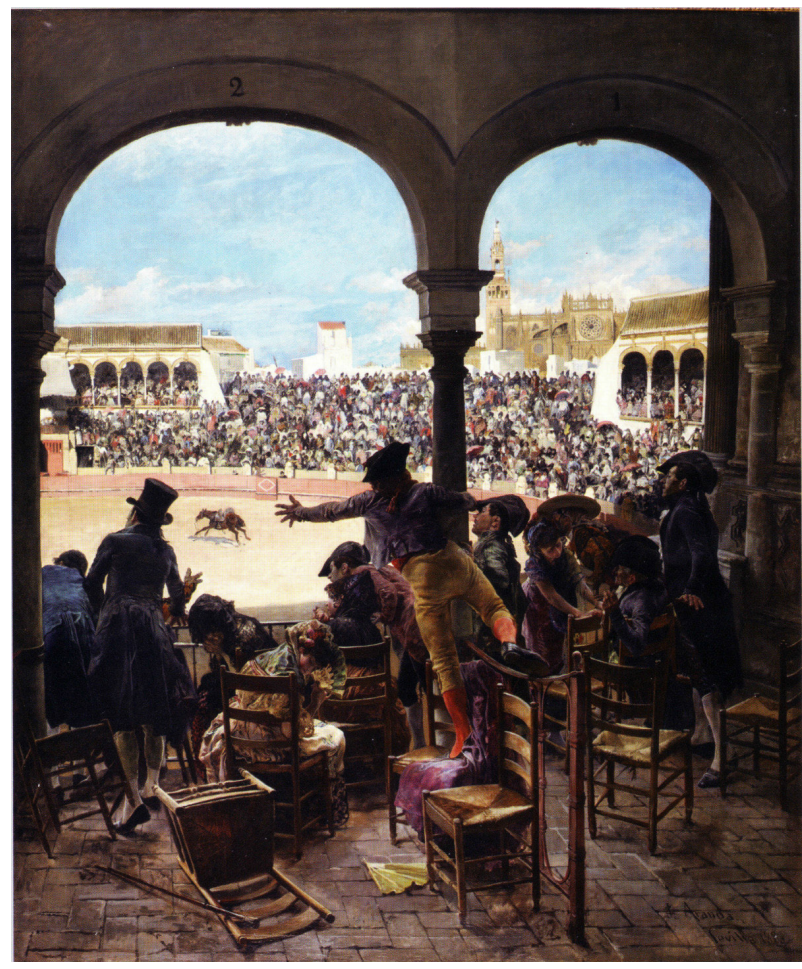

Figura 2. José Jiménez Aranda.

"En la plaza de toros de Sevilla a principios de siglo: Emoción de una cogida." O/l. 168 x $141 \mathrm{~cm} .1880$.

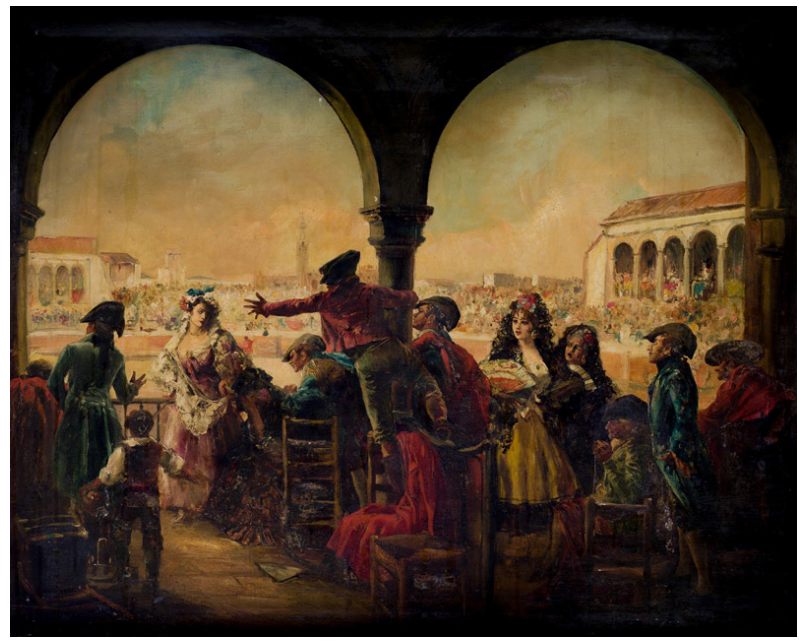

Figura 3. Eugenio Lucas Villaamil. "Un lance en la Maestranza".

O/1. 80,5 x 100 cm. c. 1885. 